\title{
Reseña
}

\section{Renato Ortiz: Notas Sobre uma Trajetória Teórica}

$\mathrm{E}$ m três obras de suma importância para a compreensão do debate da problemática cultural no Brasil, Cultura brasileira e identidade nacional (1985, 1a ed.), A moderna tradição brasileira (1988) e Mundialização e cultura (1994), Ortiz descreve não só um quadro histórico evolutivo das questões culturais, envolvendo a polêmica sobre a construção de uma identidade nacional, como também aponta a existência de uma cultura e identidade "internacional-popular", sustentada primordialmente pelos meios de comunicação de massa.

Estas notas sobre a trajetória de um autor, importante para a análise da cultura contemporânea, principalmente, nos contornos dos estudos culturais na América Latina, têm o objetivo de apresentar descritivamente as problemáticas fundamentais de um percurso teórico. Elas não têm a pretensão de compor uma análise crítica - na plenitude do termo - do pensamento de Renato Ortiz, embora se alinhavem algumas observações finais que têm esses caráter.

\section{Reconstrução Da Trajetória Teörica}

Desde o final do século XIX a temática da cultura popular esteve em evidência no cenário intelectual brasileiro. Refazendo o trajeto histórico do debate, Renato Ortiz conclui que ele se desenvolve no terreno político. $\mathrm{O}$ interesse aqui não é relatar o desenvolvimento cronológico deste embate mas apenas mencionar os eixos em torno dos quais a discussão se moveu.

O tema remete à discussão da constituição do Estado, da democracia e da organização da cultura. É associado à temática da identidade nacional e, por sua vez, nos dirije a questão da construção do Estado nacional. É relacionado, também, à questão dos intelectuais. Em diferentes épocas, intelectuais conservadores e críticos construíram diferentes representações de acordo com suas posições diante do governo em vigor. 
Além disso, o debate sobre a cultura popular no Brasil não coincide com o de cultura de massa, na medida em que esta somente se desenvolve na sua plenitude nos anos 60 , sendo que nos períodos anteriores era um fenômeno incipiente, marcado pela precariedade.

Enfim, o conceito de cultura popular no Brasil encerra duas dimensões diferentes. Refere-se à existência de classes sociais distintas e, por sua vez, a conjuntos de manifestações culturais equivalentes a estes grupos sociais. Neste sentido, se contrapõe à cultura de elite. E diz respeito à noção de povo, deslocando a ênfase para a associação entre popular e nacional, isto é, o popular passa a relacionar-se com o problema da identidade nacional. Na opinião de Ortiz, a história do conceito de cultura popular se caracterizou no Brasil, sobretudo, pela sua dimensão nacional, confundindo os dois conceitos - cultura popular e cultura nacional.

A preocupação com a temática da cultura popular remonta aos textos de Silvio Romero, Nina Rodrigues e Euclides da Cunha. A predisposição negativa que existia em relação às manifestações populares, transforma-se em elemento positivo a partir do Romantismo. Aí surge o primeiro movimento de construção do Ser nacional. No entanto, as condições sociais existentes (principalmente, a escravatura) impossibilitaram uma discussão mais ampla sobre o popular.

Posteriormente, os estudos vinculados à linha folclorista procuram refletir sobre essa problemática. A identidade nacional irá articular-se originalmente com duas noções particulares: o meio e a raça. Clima e raça explicam "a natureza indolente do brasileiro, as manifestações tíbias e inseguras da elite intelectual, o lirismo quente dos poetas da terra, o nervosismo e a sexualidade desenfreada do mulato" (Ortiz, 1986: 16).

Neste período, afirma Ortiz, a idéia de povo se confunde com a questão racial, por isso, o estudo da cultura popular se prende à pesquisa das etnias. Mas, também, são importadas teorias européias que tentam responder a seguinte questão: afinal, qual é nossa identidade?

Para equacionar o problema salienta-se o elemento mestiço. A inferioridade racial explica o porquê do atraso brasileiro, mas a noção de mestiçagem aponta para a formação de uma possível unidade 
nacional. $\mathrm{O}$ estudo da cultura popular revela a necessidade de pensar a realidade de um Estado que pretende se constituir nacionalmente.

Dando continuidade a essa tradição, na década de 30, Gilberto Freyre redireciona essa teoria. $\mathrm{O}$ conceito de raça perderá lugar para $\mathrm{o}$ de cultura e o mestiço adquirirá uma conotação positiva. A partir das primeiras décadas do século XX, o Brasil sofre mudanças profundas: urbanização, industrialização, desenvolvimento de uma classe média e de um proletariado urbano. Com a revolução de 30, o Estado procura consolidar o desenvolvimento social. Nesse quadro, as teorias raciológicas tornam-se obsoletas.

$\mathrm{Na}$ opinião de Ortiz, o trabalho de Gilberto Freyre atende a essa expectativa. Gilberto Freyre reverte a negatividade do mestiço, transformando-o em positividade no brasileiro. Para Ortiz, ele é o término de uma tradição intelectual conservadora iniciada no século XIX.

Nos anos 50 essa questão será colocada em novos termos pelos intelectuais do ISEB - Instituto Superior de Estudos Brasileiros. Rompendo com a perspectiva folclorista, formulam um ideário nacionalista estruturado basicamente a partir de dois conceitos: o de alienação e o de situação de dependência.

A situação de dependência será tratada em termos de alienação, por isso, concebe-se de imediato a contrapartida, o processo de desalienação do mundo dependente. Será preciso forjar uma consciência crítica, uma consciência nacional que se contraponha à dominação cultural. As práticas artísticas devem espelhar a realidade nacional, assim, o público pode tomar consciência de sua própria existência alienada. Assim, a discussão dá uma virada à esquerda.

A questão cultural sofre novamente alterações profundas no pós-64. Este período caracteriza-se pela crescente intervenção do Estado na esfera da cultura. Ele atua de forma sistematizada e abrangendo o território nacional, tanto no plano da repressão como no da promoção cultural.

Além disso, o desenvolvimento econômico incentivado pelo governo militar traz sérias conseqüências para a cultura: instala-se um mercado de bens culturais que se expande em nível nacional. "A emergência das indústrias culturais e a presença do Estado na esfera cultural tem conseqüências importantes. As manifestações populares devem agora se exprimir dentro de uma estrutura social que as integra a 
partir do alto. Não quero sugerir com isto que exista um processo de homogeneização ou que se implante no Brasil um homem unidimensional do tipo marcusiano. É necessário no entanto termos claro que as mudanças que ocorrem são profundas o que vai reorientar o debate sobre a cultura popular", avalia $\operatorname{Ortiz}(1984:$ 52).

Em relação 'a identidade nacional, o discurso da miscigenação racial se oficializa e é integrada uma versão moderna da cultura brasileira através do crescimento das indústrias nacionais de cultura. Segundo Ortiz, o debate cultural a partir desta etapa tende a se despolitizar, ou seja, a perspectiva mercadológica despolitiza a questão, pois se aceita o "consumo" como categoria para medir popularidade de produtos culturais.

Enfim, Ortiz afirma que a identidade é uma construção simbólica, construída por diferentes grupos sociais em diferentes momentos históricos. Assim, se estabelece uma relação entre nacional/popular e Estado: "o Estado é esta totalidade que transcende e integra os elementos concretos da realidade social, ele delimita o quadro de construção da identidade nacional. É através de uma relação política que se constitui assim a identidade; como construção de segunda ordem ela se estrutura no jogo de interação entre o nacional e o popular, tendo como suporte real a sociedade global como um todo"(Ortiz, 1986: 138). E os mediadores dessa relação são os intelectuais.

Em A moderna tradição brasileira (1988), Ortiz dá sequência a temas que já vinha trabalhando. Agora, a grande questão é: como ficam as problemáticas do nacional, do popular e da identidade nacional diante de uma moderna sociedade brasileira que se impõe como realidade e não mais como construção?

É através da discussão da cultura popular e cultura brasileira que se constrói o entendimento da formação da nacionalidade de um país da periferia. Em contrapartida, avalia Ortiz, há um relativo silêncio sobre a existência de uma cultura de massa. É somente na década de 70 que surgem os primeiros textos sobre o tema, tanto na comunicação como na sociologia.

Assumindo uma perspectiva histórica, Ortiz refaz o percurso da sociedade brasileira no que diz respeito ao consumo dos bens culturais a partir da década de 40, tratando, sobretudo, da emergência e consolidação de uma "cultura popular de massa". Para esse período inicial - anos 40 e 50 - considerase a indústria cultural incipiente, 
sendo que toda a discussão sobre a integração nacional se concentra no Estado. Já o que caracteriza a situação cultural dos anos 60 e 70 é a dimensão alcançada pelo mercado de bens culturais. É nesta fase que se consolidam os grandes conglomerados que controlam os meios de comunicação e da cultura popular de massa (Ortiz, 1988).

$\mathrm{O}$ que melhor caracteriza o advento e consolidação da indústria cultural no Brasil é a expansão da televisão. Se nos anos 50 o circuito televisivo era predominantemente local e precário tecnicamente, através do investimento do Estado na área da telecomunicação, o empresariado logo teve condições de integração do mercado.

A implantação e consolidação de uma indústria cultural e de uma sociedade moderna acaba alterando a relação entre a esfera de bens restritos e a de bens ampliados. Agora, a lógica comercial é a que prevalece e acaba determinando o espaço a ser conferido às outras formas de manifestações culturais. Uma das consequências é a despolitização do debate cultural. Entretanto, este vincula-se à própria lógica da indústria cultural. Esta é administrada pela lógica comercial, da eficiência , tornando-se menos política.

Porém, o caso brasileiro é particular. É o Estado militar quem promove o capitalismo avançado. Isto recoloca o tema da despolitização porque no período da ditadura se exigia uma certa eficiência administrativa e uma aliança com o Estado autoritário com o objetivo de integração nacional.

Por essa razão, Ortiz conclui que a consolidação da indústria cultural se dá num momento de repolitização da esfera do Estado. Aqui, o processo de despolitização, considerado inerente ao desenvolvimento da indústria cultural, acaba não se completando. Assim, o desenvolvimento da indústria cultural se beneficia de um reforço político.

A relação entre cultura e política nos remete ainda a uma discussão clássica sobre o popular e o nacional. Ortiz defende a idéia de que o advento de uma cultura popular de massa redefine a discussão. Avaliando as duas tradições que pensaram o nacional-popular, afirma: para a vertente folclorista (final do século até meados de 1930), a cultura popular era um elemento simbólico que permitia aos intelectuais tomarem consciência e expressarem a situação periférica do país em que se encontravam; já para a tradição mais politizada (a 
partir dos 50), o que se pretendia era através da cultura popular levar às classes populares uma consciência crítica dos problemas sociais.

É exatamente isto o que interessa neste texto, pois com a emergência da uma indústria cultural e a consolidação de um mercado de bens simbólicos, a concepção do que é popular tende a se modificar. $\mathrm{Na}$ moderna sociedade brasileira, popular se identifica com o que é mais consumido, serão considerados populares aqueles produtos que atingirem um grande público. Nesse sentido pode-se afirmar que a lógica mercadológica despolitiza a discussão, não é mais possível associar o 'fazer cultura' com o 'fazer política'.

Outra conseqüência é a transformação da noção de nacional. A indústria cultural equaciona a problemática da identidade nacional. Esta se identifica ao mercado, na medida em que "nação integrada" significa interligação dos consumidores potenciais espalhados pelo território nacional. Num primeiro momento, existia uma relação entre nacional e popular. A partir da consolidação de um mercado de bens simbólicos, o mercado se equivale a noção de nacional e o consumo ao de popular.

Existe, ainda, uma outra questão colocada por Ortiz nesse texto. Trata-se do confronto entre o nacional e o estrangeiro, uma temática de larga discussão na América Latina. Na opinião de Ortiz, essa questão deve ser compreendida ao longo da história brasileira através de dois períodos distintos.

Num primeiro momento, focaliza-se a precariedade na formação de uma cultura popular de massa onde é bastante forte a presença estrangeira. Mas, na opinião de Ortiz, a assimilação de contribuições variadas que são tomadas como referência, não se constitui exclusivamente em elementos de alienação nacional. (Ortiz, 1988)

Num segundo, trata-se da consolidação da cultura popular de massa. Assim, observa-se um progressivo aumento de autonomização na esfera da cultura brasileira. Depois de avaliar pelo menos duas atividades relacionadas a esse campo - a publicidade e a indústria televisiva, o autor conclui que nossa indústria cultural tem dimensões nacional e internacional. "A penetração de um produto como a telenovela na América Latina, e em vários países da Europa, aponta para uma outra direção, a de passarmos da defesa do nacional-popular para a exportação do internacional-popular" (Ortiz, 1988: 205). 
Aqui, encontra-se o germen do próximo texto do autor quando o processo de mundialização da cultura torna-se o foco de atenção. 'A primeira vista, uma reflexão sobre a globalização e a mundialização da cultura sugere que ela se afasta de particularidades, entretanto, ocorre exatamente o contrário. Assim, o autor vê que a mundialização da cultura se revela através do próprio cotidiano. Esta é uma premissa importante de reter no momento de observar a perspectiva metodológica do autor.

O movimento da mundialização, segundo Ortiz, percorre dois caminhos: o da desterritorialização e o da localização. Os sinais do primeiro são associados as características do espaço. A deslocalização da produção quando "os objetos transformam-se em compostos resultantes da combinação de pedaços dispersos aleatoriamente pelo planeta"(Ortiz, 1995: 109); a consolidação de uma cultura global cujo fulcro é o consumo; e, finalmente, quando não só os objetos mas também as referências culturais se desenraizam, ou seja, quando a sua nacionalidade conta pouco no mercado consumidor.

Este autor trabalha com a hipótese que nos encontramos diante da formação de uma memória internacional-popular. Através do consumo, é possível mostrar como este espaço se entrelaça com a memória nacional e, também, como o consumo ao se mundializar configura uma relação identitária específica.

As premissas relativas à sociedade de consumo emergem com a modernidade mas estas não reconhecem as fronteiras nacionais. A modernidade-mundo tem uma dinâmica própria. O processo de globalização e desterritorialização da cultura rompe o vínculo entre memória nacional e os objetos. Com a sua proliferação em escala mundial, estes objetos serão desenraizados de seus espaços geográficos. Assim, se o carro Ford T é símbolo da identidade americana, o automóvel é um mito do mundo moderno.

Afirmar a existência de uma identidade internacional-popular é reconhecer que na sociedade de consumo são forjadas referências culturais mundializadas. Devido à abrangência desta memória e à diversidade de grupos que envolve, a lembrança ou o re-conhecimento só se concretiza quando diz respeito ao um conjunto de objetos/valores partilhados pelo seus membros.

A memória internacional-popular funciona como um sistema de comunicação. Através de referências culturais comuns, ela estabelece 
a cumplicidade entre as pessoas. Os elementos que compõem a memória dos indivíduos são atemporais, podendo ser reciclados a qualquer momento. Enfim, a desterritorialização prolonga o presente nos espaços mundializados. Assim, nos deslocamos mas nos encontramos sempre no mesmo lugar."Ao se deparar com um universo conhecido, sua vida 'se repete', confirmando a ordem das coisas que o envolvem"(Ortiz, 1994:133).

A memória internacional-popular se revela como instância reprodutora da ordem social. As necessidades básicas do homem seriam idênticas em todos os lugares, e sua vida cotidiana se nivelaria às exigências universais de consumo.Este tipo de memória manifesta uma posicão universalista, construindo "a grande família dos homens". A mídia e as empresas transnacionais administram a memória internacional-popular. Dessa forma, a temática da identidade nacional já não pode mais desfrutar de uma centralidade.

\section{II. À Título De Conclusão}

Em 1985, em Cultura brasileira e identidade nacional, Ortiz afirma que a relação entre nacional e popular se manifesta na construção do Estado brasileiro e que o tipo dessa relação é política, pois a cada momento histórico grupos determinados de intelectuais reinterpretaram e construíram um Ser nacional.Enfatiza que a cultura encerra sempre uma dimensão de poder que lhe é interna, pressupondo um espaço de conflito onde se manifestam relações de poder.

Em 1988, em A moderna tradição brasileira, o autor avalia que o processo de consolidação da indústria cultural brasileira apresenta características peculiares porque é o Estado militar/autoritário quem promove o capitalismo e, por sua vez, a indústria cultural como o equivalente no plano cultural. Esta que naturalmente deveria seguir princípios de eficiência administrativa e preponderância da lógica comercial, atendendo exclusivamente aos imperativos do mercado, precisa conciliar esses imperativos com uma postura política de agrado ao sistema. "Os militares propõem a unificação das consciências, os empresários a integração do mercado" (Ortiz, 1988), mas estes interesses devem ser conciliados.

O advento de uma cultura popular de massa (ele faz questão de chamá-la assim) redefine a discussão. A consolidação de um mercado de bens simbólicos associa o popular ao que é mais consumido. Serão 
considerados populares aqueles produtos que atingem o grande público, portanto, isto despolitiza a questão. De outro lado, a noção de nacional se modifica: a indústria cultural é quem equaciona a identidade nacional, depois da "integração nacional", proposta pelo Estado autoritário. O nacional se identifica com mercado, na medida em que "nação integrada" significa interligação de consumidores potenciais espalhados pelo território nacional. Também, o papel dos intelectuais/profissionais da cultura se altera. Estes, diz Ortiz, podem expressar-se politicamente mas apenas enquanto cidadãos, indivíduos.

E, ainda, uma outra questão se modifica: a relação entre nacional e estrangeiro. Depois de um tempo onde se verificou uma forte presença estrangeira no período de incipiência ou precariedade da indústria cultural através da importação de quadros, conhecimentos e produtos, passa-se a uma progressiva autonomização da esfera cultural e a consolidação de indústrias nacionais de cultura. A existência de uma cultura internacional-popular tende a modificar a discussão sobre a identidade.

Se produzimos programas capazes de serem exportados e consumidos com sucesso é porque o âmbito da produção segue padrões transnacionais. No que diz respeito as identidades, Ortiz afirma sua capacidade de serem intercambiáveis por possuírem elementos de outras culturas. A identidade não se prende mais aos limites fixos do território nacional. A partir daqui já se insinua o processo de mundialização da cultura.

Entrelaçando os três textos no que diz respeito a ruptura da relação entre cultura e política, pode-se observar que o próprio autor absorve o princípio do mercado como o regulador de todo o processo. Se assumimos que o princípio maior é o mercado ou o valor de troca da mercadoria-cultura, não percebemos mais a cultura como âmbito de expressão da hegemonia, do conflito entre grupos sociais distintos, constituída por relações de poder e, portanto, política. Assim, não admitimos que a cultura ainda pressupõe um valor de uso.

Enfim, não se pode menosprezar o princípio regulador da esfera da cultura no capitalismo - o valor de troca, assim como, também, não se pode esquecer que se existe ainda uma possibilidade de diferentes usos da cultura, estes ainda comportam uma dimensão de conflito, de luta, de disputa política. 
Além disso, o consumo não pode ser o princípio exclusivo que indica a mundialização da cultura. Em seu último texto analisado (1994), o autor pauta-se por exemplos basicamente do âmbito do consumo como Coca-cola, tênis Nike, calça Lee, McDonalds, entre outras marcas de produtos para demonstrar este movimento de mundialização.

Outra observação importante trata da construção metodológica apresentada por Ortiz. No primeiro trabalho, descrito aqui, manifesta-se uma recuperação do pensamento sociológico brasileiro através de uma certa periodização onde, sob o ponto de vista cultural, são escolhidos autores representativos em cada etapa.

No segundo, o foco do trabalho gira em torno da emergência e consolidação de um mercado de bens culturais a partir da década de 40 , evidenciando suas consequências seja no plano da identidade seja na constituição de uma sociedade moderna. Metodologicamente, não são obras vistas à luz de uma cronologia que pautam esta reflexão mas uma ampla gama de dados de diversas ordens - fontes documentais como dados estatísticos, entrevistas, etc. As dimensões histórica, sociológica e antropológica estão presentes neste texto histórico-cultural.

E, no último, a compreensão da problemática nacional que perde sua posição de centralidade, diante do processo de globalização e mundialização da cultura, compõe o eixo do trabalho. Diante da premissa que a mundialização revela-se através do cotidiano o pesquisador propôs inicialmente que “... minha perspectiva foi a inversa daquela utilizada pelos antropólogos clássicos. O método de observação participante pressupunha uma aproximação daquilo que se pretendia compreender. Eu procurei tornar o próximo, distante, para desta forma apreendê-lo de maneira analítica. Escrevi este livro como um "nativo". Alguém, como o leitor, que se encontra perpassado por uma vivência mundializada. Marlboro, EuroDisney, fast-food, Hollywood, chocolates, aviões, computadores, são os traços evidentes de sua presença envolvente. Eles invadem nossas vidas, nos constrangem, ou nos libertam, e fazem parte da mobília de nosso dia-a-dia. O planeta, que no início se anunciava tão longínquo, se encarna assim em nossa existência, modificando nossos hábitos, nossos comportamentos, nossos valores."(1994: 8)

Aqui o autor apresenta uma proposta inicial de auto-etnografar-se enquanto um cidadão que vive contemporaneamente numa sociedade 
marcada pela modernidade. O etnógrafo, nesta situação, deveria ser visto como produtor e produto dos dados, construindo-se uma etnografia do próprio modo de viver.

No entanto, esta intenção frustra-se na medida em que o autor avalia que para tal é necessário desterritorializar-se, posicionando-se não mais como brasileiro ou latino-americano mas como "cidadão mundial". Perder de vista a visão territorializada, é perder o chão do cotidiano, por isso, a premissa original torna-se inoperante. Com isto perde-se uma dimensão do trabalho mas o texto cresce em amplitude e generalização.

Ana Carolina D. Escosteguy

14 Andrew Street

Cambridge MA 02139 - US

\section{Referências Bibliográficas}

Ortiz, Renato (1984), Cultura popular no Brasil: lluminados e alienados, In Revista INTERCOM, São Paulo: $n$ 49/50, jul/ago/set/out.

Ortiz, Renato (1986), Cultura brasileira e identidade nacional, São Paulo: Brasiliense.

Ortiz, Renato (1988), A moderna tradição brasileira, São Paulo: Brasiliense.

Ortiz, Renato (1994), Mundialização e cultura, São Paulo: Brasiliense. 